CLINICAL STUDY

\title{
Beneficial effect of dose escalation of Octreotide-LAR as first-line therapy in patients with acromegaly
}

\author{
Annamaria Colao, Rosario Pivonello, Renata S Auriemma, Mariano Galdiero, Silvia Savastano and \\ Gaetano Lombardi \\ Section of Endocrinology, Department of Molecular and Clinical Endocrinology and Oncology, University 'Federico II' of Naples, via S Pansini 5, 80131 \\ Naples, Italy \\ (Correspondence should be addressed to A Colao; Email: colao@unina.it)
}

\begin{abstract}
Objective: To evaluate the efficacy of dose escalation of Octreotide-long-acting repeatable (LAR) up to $40 \mathrm{mg} / \mathrm{month}$ we studied 56 newly diagnosed patients with acromegaly ( 24 women, $32 \mathrm{men}$; age 20-82 years).

Design: Analytical, observational, open and prospective.

Methods: Three months after LAR treatment beginning with a dose of $20 \mathrm{mg} / \mathrm{q} 28 \mathrm{~d}$ (every 28 days), 24 patients maintained the same dose (Group A), while 32 required a dose of $30 \mathrm{mg} / \mathrm{q} 28 \mathrm{~d}$ (Group B). The dose was further increased to $40 \mathrm{mg} / \mathrm{q} 28 \mathrm{~d}$ in 17 out of the 32 patients of Group B for another 12 months (Group C).

Results: After 24 months, serum GH and IGF-I levels decreased by $93.1 \pm 8.6 \%$ (95\% confidence limit (CL) $90.8-95.4 \%$ ) and $62.7 \pm 13.4 \%$ (95\% CL 59.1-66.3\%) respectively. Control of GH and IGF-I levels was achieved in 45 patients (80.3\%). Tumor shrinkage after 12 months was $49.8 \pm 23 \%$; the relative tumor shrinkage during the second 12 months of treatment was $35.3 \pm 13.1 \%$ and overall tumor volume was $68.1 \pm 16.5 \%$ (95\% CL 63.7-72.5\%). Glucose tolerance impaired in eight patients (14.3\%): four in Group A and four in Group C $(16.7 \%$ vs $36.4 \%, P=0.39)$. The final dose was predicted by the patient's age at diagnosis $(t=-2.2 ; P=0.032)$ and baseline tumor volume $(t=2.1$; $P=0.043)$.

Conclusion: An increase of the LAR dose up to $40 \mathrm{mg} / \mathrm{q} 28 \mathrm{~d}$ in patients resistant to $30 \mathrm{mg} / \mathrm{q} 28 \mathrm{~d}$ is followed by greater suppression of GH and IGF-I levels and tumor shrinkage without further significant impairment of glucose tolerance when compared with lower doses. These results suggest that a new dosage schedule of $40 \mathrm{mg}$ every 28 days is applied in patients with acromegaly mostly of young age and with bigger tumors who are likely to be poorly responsive to standard doses of Octreotide-LAR.
\end{abstract}

European Journal of Endocrinology 157 579-587

\section{Introduction}

Acromegaly is associated with reduced life expectancy chiefly because of cardiovascular $(60 \%)$ and respiratory diseases $(25 \%)(1)$. The most predictive survival indices are a post-treatment growth hormone $(\mathrm{GH})$ value $<5 \mathrm{mU} / \mathrm{l}$ (equal to $<2.5 \mu \mathrm{g} / \mathrm{l}$ ) associated with insulin-like growth factor-I (IGF-I) in the normal range after any treatment (1).

In the last two decades, somatostatin analogs have been considered a cornerstone of medical therapy for acromegaly. After 12 months of treatment with Octreotide-LAR (LAR), control of GH and IGF-I excess is achieved in 54 and $63 \%$ of unselected patients (2) but the proportion of subjects achieving IGF-I normalization is reported to increase significantly with time (3). Clinically significant tumor shrinkage (20-30\% versus baseline) has also been reported $(4,5)$. An average $50 \%$ tumor decrease is achieved when the drug is used exclusively, or before surgery or radiotherapy (5). After 12 months of first-line treatment with somatostatin analogs, we recently reported control of GH levels in 57.6\%, of IGF-I levels in $45.5 \%$ and a $>50 \%$ tumor shrinkage in $44.4 \%$ of 99 unselected newly diagnosed patients (6).

The dose of LAR in different studies ranged between 10 and $40 \mathrm{mg}$ every 28 days (q28d). High doses are generally administered in resistant patients who do not control GH and IGF-I excess with lower doses. Some further benefit by LAR dose increase was reported in some studies. Turner et al. (7) reported the control of GH and IGF-I levels respectively, in six and five out of the ten patients treated with $20 \mathrm{mg} / \mathrm{q} 28 \mathrm{~d}$ for 6 months and another two achieved hormone control after increasing the drug dose up to $30 \mathrm{mg} / \mathrm{q} 28 \mathrm{~d}$. Similarly, Cozzi et al. (8) reported that an up-titration of the LAR dose from 20 to $30 \mathrm{mg}$ in 40 out of 110 patients produced a better 
suppression of IGF-I but not of GH levels. We also increased the LAR dose up to $40 \mathrm{mg} / \mathrm{q} 28 \mathrm{~d}$ in 8 out of 36 patients $(23 \%)$ because of poor disease control; dose increment was followed by a further decrease of $\mathrm{GH}$ and IGF-I levels though they did not normalize during the 24 months of follow-up (9).

Data on dose escalation of Octreotide-LAR in patients with acromegaly are lacking. In the setting of a prospective evaluation of the effect of first-line treatment with LAR, we analyzed the progressive up-titration of LAR on GH and IGF-I levels and tumor volume in patients newly diagnosed with acromegaly treated with LAR for at least 24 months.

\section{Patients and methods}

\section{Patients}

From $1^{\text {st }}$ January 1995 to $31^{\text {st }}$ December 2004, 56 patients (26 women aged 20-82 years and 30 men aged 21-76 years) with active acromegaly were admitted to this study out of the 271 patients who came to our department for acromegaly during the same period. One-hundred and eighty-five patients were excluded because of: 1) primary surgery in 95 patients; 2) concomitant hyperprolactinemia requiring combined somatostatin analogs and dopamine-agonist treatment in 29 patients; 3) primary treatment with lanreotide in 44 patients (15); and 4) treatment duration being $<24$ months in 32 patients. Out of these 32 patients, 16 were withdrawn from LAR treatment because of lack of $\mathrm{GH}$ and IGF-I control before completing 24 months of treatment, 16 did not complete 24 months because the follow-up was still ongoing. Data of 12-month treatment in 45 patients (6) and those of 24-month treatment (9) have been reported in previous studies. The diagnosis of acromegaly was defined in all of the patients as previously reported (10), by high serum GH levels, not suppressible $<1 \mu \mathrm{g} / \mathrm{l}$ after glucose load and high plasma IGF-I levels for age. Based on magnetic resonance imaging (MRI), five patients had a microadenoma, ten had an enclosed macroadenoma, 26 had a macroadenoma with extrasellar extension, and 15 patients had macroadenomas with clear-cut signs of invasion of surrounding structures. The interval between assumed clinical onset and the time of treatment ranged from 24 to 360 months (median 60 months). Table 1 shows patients' profile at study entry.

All patients signed an informed consent to approve diagnostic testing, treatment decision, methods for follow-up, and treatment of the data for scientific purposes. This study has been conducted in accordance with the Helsinki II Declaration on human experimentation. This study is part of a large, prospective study to investigate the effect of first-line surgery or medical therapy (with somatostatin analogs and/or
Table 1 Patients' profile at study entry. Data are shown as mean \pm S.D. and $95 \% \mathrm{CL}$ in parentheses.

\begin{tabular}{ll}
\hline No of patients & 56 \\
Women/men & $24 / 32$ \\
Age (years) & $45 \pm 18(40-50)$ \\
Disease duration (months) & $98 \pm 81(76-119)$ \\
Serum GH levels $(\mu \mathrm{g} / \mathrm{l})$ & $55.5 \pm 44.9(43.5-67.5)$ \\
Serum IGF-I levels $(\mathrm{ULN})$ & $2.44 \pm 0.72(2.25-2.63)$ \\
Tumor volume $\left(\mathrm{mm}^{3}\right)$ & $2229 \pm 1445(1842-2816)$ \\
Fasting blood glucose levels (mmol/l) & $5.4 \pm 1.3(5.1-5.8)$ \\
Fasting serum insulin levels (mU/l) & $21.2 \pm 14.9(17.3-25.2)$ \\
HOMA-R & $5.8 \pm 6.8(3.9-7.6)$ \\
HOMA- $\beta(\%)$ & $55.6 \pm 38.4(45.3-65.9)$ \\
\hline
\end{tabular}

dopamine/agonists) on GH, IGF-I, tumor mass, cardiovascular risk markers, cardiomyopathy, hypertension, metabolic profile, and prostate diseases in all the patients coming for a diagnosis of acromegaly in our department and approved by our Ethical Committee on $14^{\text {th }}$ October 1997 (no. 60/97).

\section{Cure criteria}

The patients were considered controlled if the fasting mean GH levels were $\leq 2.5 \mu \mathrm{g} / \mathrm{l}$ in the presence of normal IGF-I levels for sex and age (11). Resistance to LAR treatment was defined as GH levels being $>2.5 \mu \mathrm{g} / \mathrm{l}$ in the presence of IGF-I levels above the gender and age reference range after 12 months of treatment with $30 \mathrm{mg} / \mathrm{q} 28 \mathrm{~d}$.

\section{Study design}

This is an analytical, observational, 24-month, open, prospective study to investigate the effect of progressive increase of Octreotide-LAR doses in patients newly diagnosed with acromegaly. Primary outcome measures were GH and IGF-I control and tumor shrinkage while the secondary outcome measure was glucose tolerance and tolerability to high doses.

\section{Study protocol}

At diagnosis and every 6 months, 24-48 h before changes in treatment doses were applied, the following were measured:

1. Serum IGF-I levels twice in a single sample at the time 0 of the $\mathrm{GH}$ profile; $\mathrm{GH}$ levels calculated as the mean value of three to six samples drawn every $30 \mathrm{~min}$; the average value was considered for the statistical analysis.

2. Tumor volume on MRI studies performed on clinical $1 \mathrm{~T}$ and $1.5 \mathrm{~T}$ scanners using $\mathrm{T} 1$-weighted gradient recalled-echo in the sagittal and the coronal planes, as already reported $(6,9,12)$. The acquisitions were repeated before and after the 
administration of $0.1 \mathrm{mmol}$ gadolinium chelate (diethylene-triamine pentacetate). In all patients, MRI was performed at diagnosis and after 6,12 , and 24 months of treatment. The maximal sagittal, axial, and coronal diameters were measured, then tumor volume was calculated by the De Chiro and Nelson formula $(($ volume $=$ sagittal $\times$ coronal $\times$ axial diameters $) \times \pi / 6)$. According to previous studies $(6,9)$ on post-treatment MRI, tumor shrinkage was assessed as the percent decrease of tumor volume when compared with baseline.

3. Glucose tolerance by assaying glucose and insulin levels at fasting. Only at diagnosis glucose and insulin were also measured every $30 \mathrm{~min}$ for $2 \mathrm{~h}$ after the oral administration of $75 \mathrm{~g}$ glucose diluted in $250 \mathrm{ml}$ saline solution. In four patients, the glucose load was not performed because of overt diabetes (fasting glucose was above $7 \mathrm{mmol} / \mathrm{l}$ at two consecutive measurements) (13). Diabetes mellitus was diagnosed in another eight patients when $2 \mathrm{~h}$ after the oGTT glucose was $>11 \mathrm{mmol} / \mathrm{l}$ (13). Impaired glucose tolerance (IGT) when glucose level was between $\geq 7.8$ and $<11 \mathrm{mmol} / \mathrm{l}, 2 \mathrm{~h}$ after the oGTT and/or impaired fasting glucose when glucose level was between 5.6 and $6.9 \mathrm{mmol} / \mathrm{l}$ at fasting were diagnosed in 20 patients (13). Glucose tolerance was normal (below $5.6 \mathrm{mmol} / \mathrm{l}$ at fasting) in 24 patients. To predict insulin resistance homeostatic model assessment (HOMA)-R (\%)) and $\beta$-cell function (HOMA- $\beta$ (\%)) was used in accordance with Matthews et al. (14). By assuming that normalweight healthy subjects aged $<35$ years have a HOMA- $\beta$ of $100 \%$ and a HOMA-R of 1 , the values for individual patients can be assessed from the insulin and glucose concentrations by the following formulae: HOMA-R = (insulin $(\mathrm{mU} / \mathrm{l}) \times$ fasting glucose $(\mathrm{mmol} / \mathrm{l})) / 22.5$ and HOMA- $\beta(\%)=$ $(20 \times$ insulin $(\mathrm{mU} / \mathrm{l})) /(\mathrm{glucose}(\mathrm{mmol} / \mathrm{l})-3.5)$.

\section{Treatment protocol}

Before starting therapy, all patients received an acute test with s.c. Octreotide at a dose of $0.1 \mathrm{mg}$ in the morning after an overnight fast and at least $2 \mathrm{~h}$ bedrest, to investigate individual patient's tolerability to somatostatin analogs (15). Then, all patients were treated with Octreotide-LAR i.m. at an initial dose of $20 \mathrm{mg} / \mathrm{q} 28 \mathrm{~d}$ for three months. Subsequently, LAR treatment was maintained at the same dose in patients achieving GH levels $\leq 2.5 \mu \mathrm{g} / \mathrm{l}$ and IGF-I levels in the normal range (Group A), or increased up to $30 \mathrm{mg}$ every 28 days in patients with IGF-I levels above the normal range and/or GH levels less than or greater than $2.5 \mu \mathrm{g} / \mathrm{l}$. After another 9 months of treatment with $30 \mathrm{mg} / \mathrm{q} 28 \mathrm{~d}$, the dose was maintained in 15 patients achieving GH levels $\leq 2$.homeostatic model assessment $5 \mu \mathrm{g} / \mathrm{l}$ and IGF-I levels in the normal range (Group B), while it was further increased to $40 \mathrm{mg} / \mathrm{q} 28 \mathrm{~d}$ if fasting $\mathrm{GH}$ levels were still $>2.5 \mu \mathrm{g} / \mathrm{l}$ and/or IGF-I levels were above the normal range (Group C).

\section{Assays}

From $1^{\text {st }}$ January 1995 to $31^{\text {st }}$ December 2001, serum $\mathrm{GH}$ levels were measured by IRMA (Sorin, Saluggia, Italy); the sensitivity of the assay was $0.2 \mu \mathrm{g} / \mathrm{l}$ and the intra- and inter-assay coefficients of variation (CVs) were respectively 4.5 and $7.9 \%$. From $1^{\text {st }}$ January 2002 , serum GH levels were measured by IRMA using commercially available kits (HGH-CTK-IRMA Sorin). The sensitivity of the assay was $0.05 \mu \mathrm{g} / \mathrm{l}$. The intraand inter-assay CVs were 4.3 and $8.5 \%$ respectively. Serum IGF-I was measured by IRMA after ethanol extraction, using Diagnostic System Laboratories Inc. (Webster, TX, USA). The normal range in $\leq 20,21-30-$, 31-40-, 41-50-, 51-60-, 61-70-, and >70-year-old men was 180-625, 118-475, 102-400, 100-306,
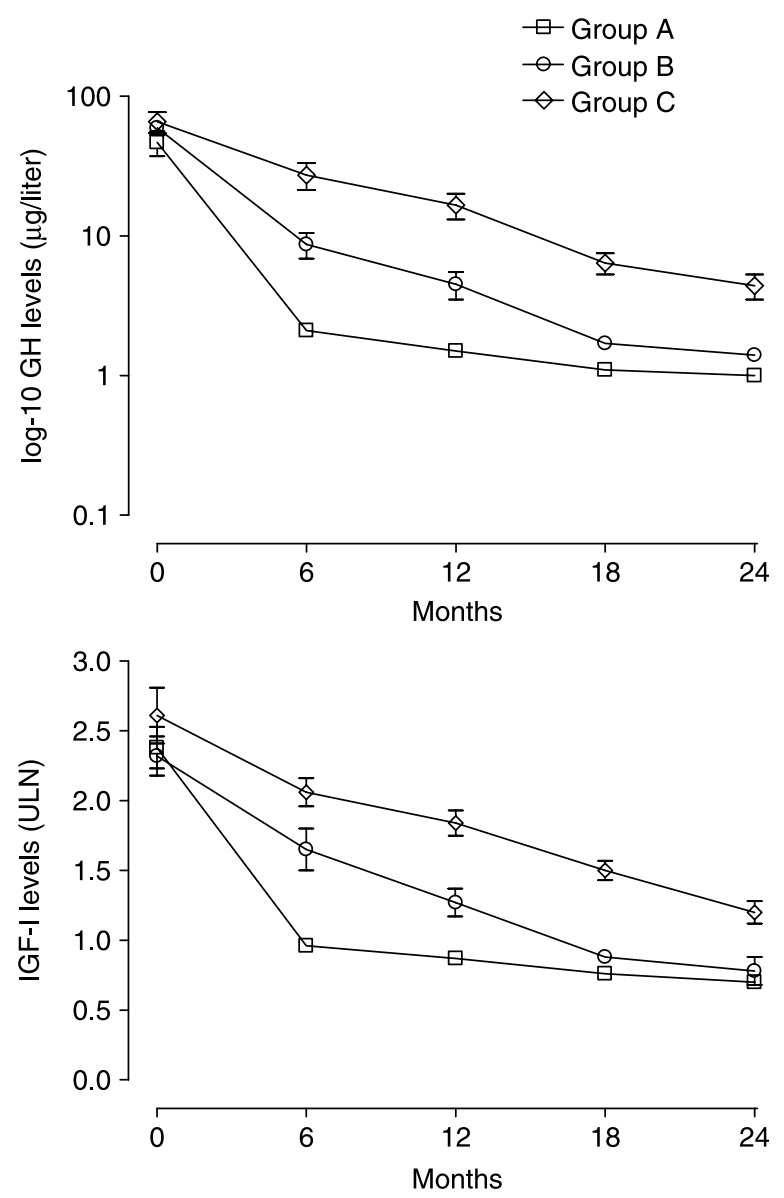

Figure 1 Profile of GH (top) and IGF-I levels (expressed as times above the upper limit of normal (ULN); bottom) during the study according with the final dose of Octreotide-LAR. 
95-270, 88-250, and $78-200 \mu \mathrm{g} / \mathrm{l}$ respectively, whereas in women it was $151-530,118-450$, 100-390, 96-288, 90-250, 82-200, and $68-188 \mu \mathrm{g} / \mathrm{l}$ respectively. The sensitivity of the assay was $0.8 \mu \mathrm{g} / \mathrm{l}$. The intra-assay CVs were $3.4,3.0$, and $1.5 \%$ for low, medium, and high points of the standard curve respectively. The inter-assay $\mathrm{CVs}$ were $8.2,1.5$, and $3.7 \%$ for low, medium, and high points of the standard curve. IGF-I data are shown as the upper limit of normal range ((ULN) normal $\leq 1)$.

\section{Statistical analysis}

The data were analyzed using MedCalc Software for Windows (MedCalc, Mariakerke, Belgium). Data are reported as mean \pm s.D. unless otherwise specified. The comparison between Group A versus Groups B + C was performed using the Mann-Whitney $U$ test; two-sided $P$ values are reported as exact probability adjusted for ties. The comparison among Groups A, B, and C was performed by Kruskal-Wallis test followed by the Dunn's multiple comparison test. The comparison of the data collected at baseline and during treatment ( 0 vs 6 vs 12 vs 18 and vs 24 months) was performed by the Kruskal-Wallis test followed by the Dunn's multiple comparison test. The $\chi^{2}$ test was used to compare categorical variables. The significance was set at $5 \%$. Correlation was analyzed by calculating the Spearman rank correlation coefficient; two-sided $P$ values are shown. The multiple regression analysis was performed in order to indicate the best predictor of dose requirement among baseline characteristics; in this analysis were included only the variables having a Spearman $\rho$ of $<0.01$.

\section{Results \\ Octreotide-LAR dosages}

Three months after beginning LAR treatment, 24 $(42.9 \%)$ of the 56 patients maintained a dose of $20 \mathrm{mg} \mathrm{mg/q28d} \mathrm{(Group} \mathrm{A),} \mathrm{while} 32$ (57.1\%) required a dose of $30 \mathrm{mg} / \mathrm{q} 28 \mathrm{~d}$ (Group B); after completion of out 12 months, $17(53.1 \%)$ out of the 32 patients of Group $\mathrm{B}$ required further increase of the dose up to $40 \mathrm{mg} / \mathrm{q} 28 \mathrm{~d}$ for another 12 months (Group C).

\section{Primary outcome measures}

Control of GH and IGF-I levels GH and IGF-I levels decreased during LAR treatment (Fig. 1); overall, after 24 months, serum GH and IGF-I levels decreased by $93.1 \pm 8.6 \%$ (95\% CL 90.8-95.4\%) and $62.7 \pm 13.4 \%$ (95\% CL 59.1-66.3\%) respectively. Patients of Groups B and $\mathrm{C}$ were younger and had shorter disease duration than those of Group A, while baseline GH and IGF-I levels were similar (Table 2).

After 24 months of treatment, control of GH and IGFI excess was achieved in all patients of Groups A and B (as expected) and in six patients of Group C (35.3\%) so

Table 2 Primary and secondary outcome measures according with the final dose of Octreotide-LAR treatment.

\begin{tabular}{|c|c|c|c|c|}
\hline Final dose of Octreotide-LAR & Group A 20 mg & Group B $30 \mathrm{mg}$ & Group C 40 mg & $\boldsymbol{P}$ \\
\hline No. of patients & $24(42.8 \%)$ & $15(26.8 \%)$ & $17(30.4 \%)$ & \\
\hline Women/Men & $10 / 17$ & $7 / 8$ & $9 / 8$ & \\
\hline Age (years) & $53 \pm 17$ & $37 \pm 15^{\mathrm{A}}$ & $40 \pm 13^{A}$ & 0.003 \\
\hline Disease duration (months) & $137 \pm 96$ & $63 \pm 42^{\mathrm{A}}$ & $73 \pm 45^{\mathrm{A}}$ & 0.003 \\
\hline Baseline $\mathrm{GH}$ levels $(\mu \mathrm{g} / \mathrm{l})$ & $46.7 \pm 49.4$ & $59.5 \pm 27.2$ & $65.7 \pm 46.4$ & 0.35 \\
\hline Final GH levels $(\mu \mathrm{g} / \mathrm{l})$ & $1.1 \pm 0.5$ & $1.4 \pm 0.4$ & $4.4 \pm 3.7^{\mathrm{B}}$ & $<0.0001$ \\
\hline Final GH decrease (\%) & $94.0 \pm 99$ & $95.8 \pm 5.9$ & $90.6 \pm 8.3$ & 0.21 \\
\hline Baseline IGF-I levels (ULN) & $2.38 \pm 0.80$ & $2.32 \pm 0.54$ & $2.61 \pm 0.67$ & 0.47 \\
\hline Final IGF-I levels (ULN) & $0.70 \pm 0.1$ & $0.78 \pm 0.11$ & $1.22 \pm 0.33^{\mathrm{B}}$ & $<0.0001$ \\
\hline Final IGF-I decrease (\%) & $69.1 \pm 9.6$ & $65.0 \pm 7.7$ & $51.2 \pm 13.6^{\mathrm{B}}$ & $<0.0001$ \\
\hline Baseline tumor volume $\left(\mathrm{mm}^{3}\right)$ & $1189 \pm 1198$ & $2130 \pm 953^{A, C}$ & $2952 \pm 1181^{\mathrm{A}}$ & $<0.0001$ \\
\hline Final tumor volume $\left(\mathrm{mm}^{3}\right)$ & $535 \pm 414$ & $592 \pm 334$ & $1342 \pm 890^{\mathrm{B}}$ & $<0.0001$ \\
\hline Final tumor shrinkage (\%) & $75.3 \pm 13.8$ & $71.9 \pm 10.7$ & $53.0 \pm 15.9^{\mathrm{B}}$ & $<0.0001$ \\
\hline Baseline glucose levels (mmol/l) & $5.8 \pm 1.7$ & $5.0 \pm 0.5$ & $5.1 \pm 0.6$ & 0.073 \\
\hline Final glucose levels $(\mathrm{mmol} / \mathrm{l})$ & $5.2 \pm 0.4$ & $5.3 \pm 0.3$ & $5.4 \pm 0.3$ & 0.19 \\
\hline Baseline insulin levels (mU/l) & $25.5 \pm 18.1$ & $16.0 \pm 6.5$ & $16.2 \pm 9.5$ & 0.039 \\
\hline Final insulin levels (mU/l) & $7.7 \pm 1.6$ & $7.5 \pm 1.4$ & $7.0 \pm 1.3$ & 0.31 \\
\hline Baseline HOMA-R & $7.7 \pm 9.2$ & $3.7 \pm 1.8$ & $3.6 \pm 2.2$ & 0.063 \\
\hline Final HOMA-R & $1.8 \pm 0.4$ & $1.8 \pm 0.3$ & $1.7 \pm 0.3$ & 0.26 \\
\hline Baseline HOMA- $\beta$ (\%) & $63.9 \pm 37.4$ & $42.7 \pm 34.2$ & $45.3 \pm 41.8$ & 0.14 \\
\hline Final HOMA- $\beta(\%)$ & $9.7 \pm 6.5$ & $8.5 \pm 5.6$ & $6.3 \pm 5.1$ & 0.68 \\
\hline Prevalence of GH control (pts no. (\%)) & $27(100)$ & $15(100)$ & $6(\overline{35} .3)$ & $<0.0001$ \\
\hline Median time to achieve GH control (months) & 6 & $18^{\mathrm{A}}$ & $15^{\mathrm{A}}$ & $<0.0001$ \\
\hline Prevalence of IGF-I control (pts no. (\%)) & $27(100)$ & $15(100)$ & $5(29.4)$ & $<0.0001$ \\
\hline Median time to achieve IGF-I control (months) & 6 & $18^{\mathrm{A}}$ & $18^{\mathrm{A}}$ & $<0.0001$ \\
\hline
\end{tabular}

A, $P<0.01$ versus Group A; B, $<0.01$ versus Group A and B; C, $<0.01$ versus Group C. 
that 45 patients $(80.3 \%)$ achieved control of $\mathrm{GH}$ and IGF-I excess.

At baseline, the 45 patients achieving disease control with any dose, had significantly lower GH levels than the 11 non-controlled $(48.7 \pm 42.6$ vs $82.6 \pm 46.4 \mu \mathrm{g} / \mathrm{l}$; $P=0.03)$, while IGF-I levels were similar $(2.36 \pm 0.72$ vs $2.78 \pm 0.65 \mathrm{ULN} ; P=0.065)$.

In patients of Groups A and B, suppression of GH and IGF-I levels was significantly higher in the first than in the subsequent 12 months of treatment; no difference was observed in the 17 patients of Group C (Fig. 2).

Tumor shrinkage At baseline, tumor volumes of Group A patients were significantly smaller than those of Groups B and C (Table 2). Overall, after 24 months, the tumor volume was decreased by $68.1 \pm 16.5 \%$ (95\% CL 63.7-72.5\%). Total tumor shrinkage after 24 months was significantly lower in patients of Group C than that of Groups A and B (Table 2, Fig. 3).
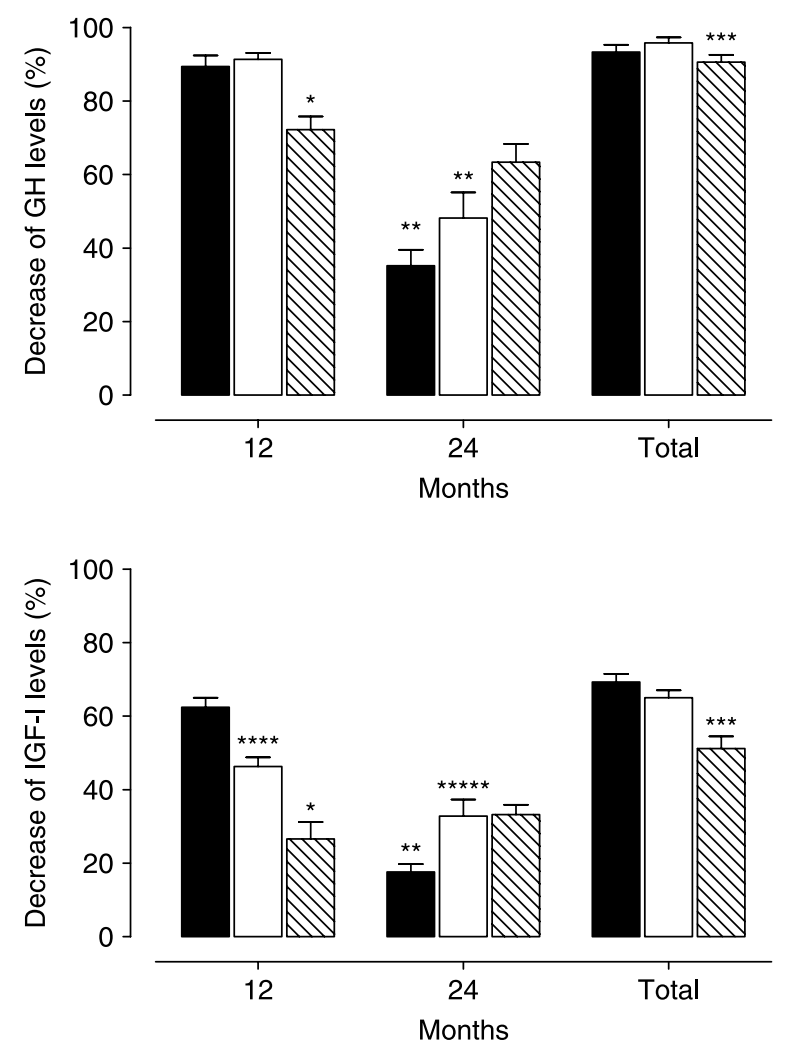

Figure 2 Percent suppression of GH (top) and IGF-I levels (bottom) in the Groups A, B, and C from baseline to 12 months of treatment (12), from 12 to 24 months of treatment (24) and total suppression (from baseline to 24 months of treatment). ${ }^{\star} P<0.01$ vs 12 months Groups $A$ and $B ;{ }^{* \star} P<0.01$ vs 12 months suppression in individual groups; ${ }^{* \star \star} P<0.05$ vs 24 months Groups $A$ and $B ;{ }^{* * \star \star} P<0.05$ vs 12 months Group $A ;{ }^{\star \star \star \star \star} P<0.05$ vs 12 months Group B.
The partial tumor shrinkage after 12 months was significantly higher in the patients of Group A than that of Groups B and C (Fig. 3).

Patients achieving disease control had smaller tumor volumes at baseline $\left(2021 \pm 1078\right.$ vs $3079 \pm 2318 \mathrm{~mm}^{3}$; $P=0.028)$ and achieved a greater tumor shrinkage at end-treatment $(72.6 \pm 13.8$ vs $49.8 \pm 13.9 \%$; $P<0.0001)$ than those who did not.

\section{Secondary outcome measures}

Glucose tolerance At study entry, 24 (42.8\%) patients had normal glucose tolerance, 20 (35.7\%) had IGT, and $12(21.4 \%)$ had diabetes mellitus; only one patient was receiving metformin treatment at the diagnosis of acromegaly. Groups B and $\mathrm{C}$ patients had lower insulin levels and HOMA-R index than those of Group A. During the study, fasting glucose levels significantly increased both in the patients with normal glucose tolerance and in those with IGT, while they decreased significantly in patients with diabetes (Fig. 4). In these latter patients, however, treatment for diabetes was started in the 11 previously untreated patients, four with insulin and seven with metformin. Insulin levels were suppressed in all groups during the study (Fig. 4).

At the end of the study, out of the 24 patients with normal glucose tolerance at diagnosis, six (25\%) developed IGT; of the 20 patients with IGT, 14 (70\%) remained IGT, two developed overt diabetes (10\%) and started a treatment with metformin, and four $(20 \%)$ normalized glucose tolerance; out of the 12 patients with diabetes eight remained diabetic (66.7\%) and maintained their treatment (insulin in five and metformin in three) and four (28.3\%) improved to IGT and stopped metformin treatment. HOMA-R and HOMA- $\beta$ were significantly reduced during treatment

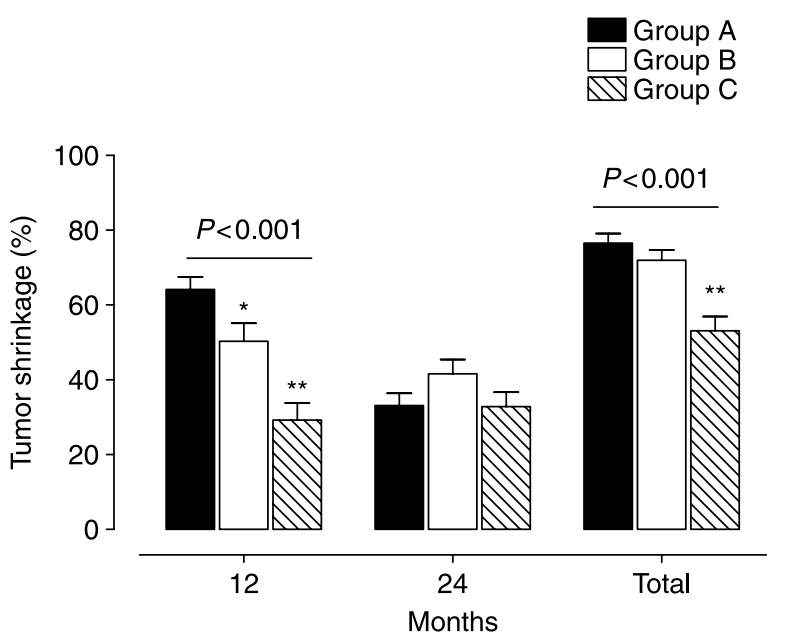

Figure 3 Percent tumor shrinkage in the Groups A, B, and C from baseline to 12 months of treatment (12), from 12 to 24 months of treatment (24) and total tumor shrinkage (from baseline to 24 months of treatment). ${ }^{*} P<0.01$ versus same time Group A; ${ }^{\star \star} P<0.01$ versus same time Group $A$ and $B$. 

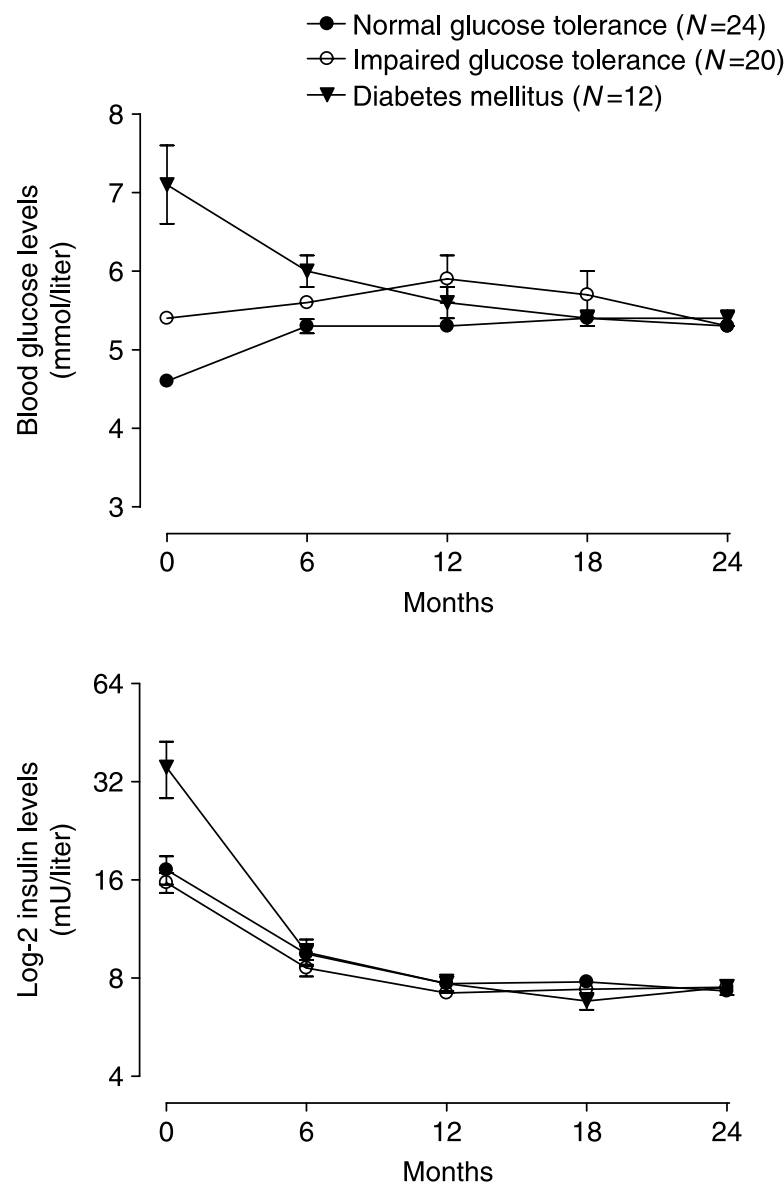

Figure 4 Profile of fasting glucose (top) and insulin levels (bottom) during the study and according with glucose tolerance status at diagnosis.

independently from the dose of Octreotide-LAR used (Table 2) and disease control (data not shown). Of the patients showing impairment of glucose tolerance, four were in Group A and four in Group C (16.7\% vs 36.4\%, $P=0.39$ ).

Tolerability Octreotide-LAR treatment was well tolerated by most patients. After the first two to three injections, abdominal discomfort was reported by $36(64.3 \%)$, steatorrhea by eight (14.3\%), flatulence by $25(44.6 \%)$, and hair loss by seven women $(29.2 \%)$. These side effects spontaneously disappeared in all cases except ten $(17.9 \%)$ who required treatment with pancreatic enzymes for 3-6 months. Hair loss stopped after 3-6 months.

At diagnosis, asymptomatic gallstones were detected in 15 patients, while at end-treatment they appeared in another 15 patients $(26.8 \%)$.

\section{Correlation analysis}

The final LAR dose was significantly correlated with the patients' age at diagnosis $(\rho=-0.41$,
$P=0.002)$, baseline $\mathrm{GH}(\rho=0.39 ; P=0.003)$ and IGF-I levels $(\rho=0.28 ; P=0.039)$, baseline tumor volume $(\rho=0.37 ; \quad P=0.005)$, final $\mathrm{GH} \quad(\rho=0.77$; $P<0.0001)$ and IGF-I levels $(\rho=0.72 ; P<0.0001)$, percent IGF-I suppression $(\rho=0.42 ; P=0.001)$, final tumor volume $(\rho=0.52 ; P<0.0001)$, and percent tumor shrinkage $(\rho=-0.52 ; P<0.0001)$. The final dose was also correlated with the percent increase of glucose $(\rho=0.34 ; P=0.01)$ and decrease of insulin levels $(\rho=0.31 ; P=0.021)$.

The final dose was predicted by patients' age at diagnosis $(t=-2.2 ; P=0.032)$ and baseline tumor volume $(t=2.1 ; P=0.043)$.

\section{Discussion}

The results of the present study show that increasing LAR doses of up to $40 \mathrm{mg} / \mathrm{q} 28 \mathrm{~d}$ induces a further decrease of GH and IGF-I levels and tumor shrinkage in patients resistant to $30 \mathrm{mg}$ at the same injections interval, thus inducing disease control in $25 \%$ of them. The patients requiring such high doses are younger, have higher GH levels and bigger tumors at diagnosis than those who achieve disease control with lower doses. Overall, only a minority of patients with normal glucose tolerance at diagnosis impaired their glucose tolerance at the end of the 24-month treatment; increased dose up to $40 \mathrm{mg} / \mathrm{q} 28 \mathrm{~d}$ did not worsen glucose tolerance more than a dose of $20 \mathrm{mg} / \mathrm{q} 28 \mathrm{~d}$.

The primary objective of therapy in acromegaly is to reverse symptoms and signs of the disease, treat the underlying cause, prevent disease recurrence, and improve long-term survival (16). It is presently accepted that achieving GH levels of $<2 \mu \mathrm{g} / \mathrm{l}$ is associated with near-normal life expectancy (1). Surgery via the transsphenoidal route with or without adjuvant radiotherapy is still considered the treatment of choice, but even despite recent advances the overall surgical cure rate remains around $50 \%$ and radiotherapy may take 5-10 years to lower GH to safe levels (17). Radiotherapy has the additional disadvantage of inducing a high incidence of hypopituitarism, which itself is associated with excess mortality $(18,19)$. These concerns have led to a reappraisal of somatostatin analogs therapy for acromegaly, not just as an adjunct to surgery and radiotherapy, but for using as first-line primary therapy (20).

In this setting, Octreotide-LAR is efficacious in the medical approach to acromegaly. As shown in a recent meta-analysis (2), control of GH and IGF-I secretions is reported in 57 and $67 \%$ respectively, after OctreotideLAR therapy with similar efficacy with respect to $\mathrm{GH}$ levels and only marginally greater IGF-I normalization when adjunctive therapy was compared with first-line. In the present study, we confirm that first-line Octreotide-LAR therapy for 12 months (a period of 
treatment similar to that reported in the meta-analysis (2)) induced control of GH and IGF-I levels in 55.3 and $44.6 \%$ respectively. Cure rate increased up to $80.3 \%$ with continuous treatment for 24 months and up-titration of the drug dose to $40 \mathrm{mg} / \mathrm{q} 28 \mathrm{~d}$. However, if we include in the calculation of treatment efficacy the 16 patients who were withdrawn from treatment prior to 24 months, the overall disease control decreased to $62.5 \%$, still remaining higher than that observed at 12 months.

The advantage of up-titration of the dose of Octreotide-LAR has been poorly investigated; besides the evidence that higher doses are associated with worse responsiveness (2), some further benefit in suppressing GH and IGF-I levels by increasing the dose from 20 to $30 \mathrm{mg} / \mathrm{q} 28 \mathrm{~d}$ had been reported (7-9, $21,22)$. Of the 32 patients requiring an increase of the dose from 20 to $30 \mathrm{mg} / \mathrm{q} 28 \mathrm{~d}$ after the initial 3 months of treatment, 15 achieved disease control within 12 months and another six in the second 12 months after further increase of the dose to $40 \mathrm{mg} / \mathrm{q} 28 \mathrm{~d}$. These data are in line with those recently reported by Cozzi et al. (8) and Ayuk et al. (23), who reported a very high success rate $(67-70 \%$ of cases) after prolonged Octreotide-LAR treatment given first-line or adjunctive therapy with a maximal dose of $30 \mathrm{mg} / \mathrm{q} 28 \mathrm{~d}$. Apparently, the prevalence of disease control in the present study and in the previous ones $(8,23)$ is not different: however, treatment duration lasted 48 months in the former and 41 months in the latter (that also included patients treated as second-line). Thus, one implication of the results reported in the present study is that increase of the dose could shorten the period required for $\mathrm{GH}$ and IGF-I control.

However, the analytical collection of the data in the present study allowed us also to show that some further suppressive effect is obtained in patients maintaining the same dose during the study also. In fact, in the 24 patients of Group A, who received the same dose of $20 \mathrm{mg} / \mathrm{q} 28 \mathrm{~d}$ for 24 months (four of them indeed decreased the dose to $10 \mathrm{mg}$ after 12 months but were considered together with the other patients), we observed a further suppression both of GH and IGF-I levels (by a median of 32.7 and $15.4 \%$ respectively) during the second 12 months of treatment. Further hormone suppression was obtained even if all patients achieved control of GH and IGF-I levels during the first 12 months of treatment. Another clinically important observation is that increase of the dose from 30 to $40 \mathrm{mg} / \mathrm{q} 28 \mathrm{~d}$ after 12 months of treatment in 17 patients was accompanied by control of GH and IGF-I levels in six patients and by an overall median $\mathrm{GH}$ suppression of $65.4 \%$ and IGF-I suppression of $29.6 \%$. The dose of $40 \mathrm{mg} / \mathrm{q} 28 \mathrm{~d}$ induced a success rate that can be considered little since only six out of 17 patients achieved disease control in the 12 months of treatment. However, the increment of the dose further decreased significantly both GH and IGF-I levels thus suggesting that prolonged treatment at the same high dose could increase the success rate of the treatment in a shorter period of time, as mentioned previously. In fact, since further suppression of GH and IGF-I levels during the second year of treatment (by 40.9 and 28.1\% respectively) was also found in the patients who maintained a dose of $30 \mathrm{mg} / 28 \mathrm{~d}$, out of the six patients achieving disease control with the dose increment to $40 \mathrm{mg} / \mathrm{q} 28 \mathrm{~d}$ only three would have achieved the same effect maintaining the $30 \mathrm{mg}$ dose. The availability of $\mathrm{GH}$-receptor antagonist in the recent years has provided another efficacious tool to control IGF-I excess in $75-100 \%$ of resistant patients with acromegaly (24-26). This suggests that prolonging OctreotideLAR up to $40 \mathrm{mg}$ could not be anymore necessary in resistant patients. However, increase in tumor size can be experienced by patients with large tumors that did shrink during somatostatin analogs therapy (26); some increase in liver function tests is also reported during $\mathrm{GH}$-receptor antagonist treatment (27).

Shrinkage of tumor mass by $\sim 50 \%$ is reported in patients with acromegaly treated with somatostatin analogs given first-line $(4,5)$. In a recent prospective study, we reported tumor shrinkage $>25 \%$ in $75.5 \%$ and $>50 \%$ in $44.4 \%$ of 99 patients after 12 months of treatment with somatostatin analogs (6). In the present study, we showed that increasing the drug dose up to $40 / \mathrm{q} 28 \mathrm{~d}$ induced further tumor shrinkage when compared with the lower dose. We also showed that prolonged treatment for 24 months in the entire series induced a greater tumor shrinking effect than a 12-month treatment, and that patients treated with the same dose from 6 to 24 months achieved further tumor shrinkage. These results suggest that in patients partially responsive to Octreotide-LAR increasing the drug dose and prolonging the period of treatment induce greater tumor shrinkage than in the first period of treatment with a lower dose. This also demonstrates that the observation reported in the meta-analysis by Freda et al. (2) showing that increasing the number of months of therapy beyond 6 months was not associated with an increased likelihood of tumor shrinkage was not entirely appropriate but was essentially drawn from data originated by short-term treatments reported in the majority of the studies.

The most important shortcoming of prolonged somatostatin analogs treatment is the impairment of glucose tolerance. Although most studies have shown no significant effect on glucose tolerance, some groups reported raised glucose or glycosylated hemoglobin levels after 6 months of treatment $(28,29)$. In our study, the overall glucose tolerance did not change, but $25 \%$ of patients with normal glucose tolerance at baseline developed IGT, and 10\% with IGT developed overt diabetes. Besides, $20 \%$ of patients with IGT normalized their glucose tolerance and $28.3 \%$ of those with diabetes did not require glucose-lowering drugs 
anymore during Octreotide-LAR treatment. To note this, the dose of different treatments for diabetes was increased in five out of the 12 diabetic patients $(41.7 \%)$ at diagnosis. In all patients, insulin sensitivity improved but $\beta$-cell function was reduced. Even if these results are reassuring, it should be reminded that treatment with GH-antagonist specifically improves glucose tolerance (30). Thus, in patients with diabetes, first-line treatment with somatostatin analogs should balance tumor size reduction with a possible worsening of glucose tolerance that requires an increase in the doses of glucoselowering drugs in almost half of the patients.

Generally, the treatment with Octreotide-LAR, even at high doses, is very well tolerated as also shown in the present study. New gallstone formation has been reported in $\sim 24 \%$ of patients treated with depot somatostatin analogs (31), as confirmed in this study $(25.3 \%)$. Abdominal discomfort is common at treatment beginning and generally subsides spontaneously without any specific treatment except in a minority of cases (21.1\% of the present series).

Some studies are reporting on the beneficial effects of combination schemes of treatment including somatostatin analogs plus dopamine-agonists (32) or once weekly GH-antagonist (33). Both GH-antagonist and dopamine-agonists have some limitations since they induce side effects, and have never been reported to induce further tumor shrinkage. Thus, even if increase of the dose of LAR up to $40 \mathrm{mg} / \mathrm{q} 28 \mathrm{~d}$ might have similar efficacy of other treatment schemes, we suggest that it would target hormone excess and tumor shrinkage in the same time with no evidence of worsening of known side effects.

\section{Conclusion}

The results of the present study show that increase of Octreotide-LAR dose up to $40 \mathrm{mg} / \mathrm{q} 28 \mathrm{~d}$ in patients resistant to the $30 \mathrm{mg}$ dose is followed by greater suppression of GH and IGF-I levels and induces greater tumor shrinkage without further impairment of glucose tolerance when compared with lower doses. Besides, we demonstrated that patients treated for 24 months at the same dose had further tumor shrinkage when compared with 12-month follow-up. Altogether, these results suggest that a new dosage schedule is applied in patients with acromegaly treated first-line with Octreotide-LAR by starting with a $30 \mathrm{mg} / \mathrm{q} 28 \mathrm{~d}$ and down- or up-titrated to 20 or $40 \mathrm{mg}$ in accordance with individual patient's response of GH and IGF-I levels. We also support modern acromegaly treatment guidelines indicating that prolonged treatment is performed in patients bearing large tumors that do not require immediate surgical debulking because of neurological deficits.

\section{Acknowledgements}

This study did not receive any support from pharmaceutical industries. A C and G L received unrestricted grants from Ipsen, Italfarmaco, and Novartis to the Department of Molecular and Clinical Endocrinology of the University Federico II of Naples to support research projects in the field of neuroendocrinology. The paper has been registered in the www.clinicaltrials.gov database with the ID NCT00461149.

\section{References}

1 Melmed S. Medical progress: acromegaly. New England Journal of Medicine $20063552558-2573$.

2 Freda PU, Katznelson L, van der Lely AJ, Reyes CM, Zhao S \& Rabinowitz D. Long-acting somatostatin analog therapy of acromegaly: a meta-analysis. Journal of Clinical Endocrinology and Metabolism 200590 4465-4473.

3 Cozzi R, Montini M, Attanasio R, Albizzi M, Lasio G, Lodrini S, Doneda P, Cortesi L \& Pagani G. Primary treatment of acromegaly with octreotide LAR: a long-term (up to nine years) prospective study of its efficacy in the control of disease activity and tumor shrinkage. Journal of Clinical Endocrinology and Metabolism 2006 91 1397-1403.

4 Bevan JS. The antitumoral effects of somatostatin analog therapy in acromegaly. Journal of Clinical Endocrinology and Metabolism $2005901856-1863$.

5 Melmed S, Sternberg R, Cook D, Klibanski A, Chanson P, Bonert V, Vance M-L, Rhew D, Kleinberg D \& Barkan A. A critical analysis of pituitary tumor shrinkage during primary medical therapy in acromegaly. Journal of Clinical Endocrinology and Metabolism 2005 $904405-4410$.

6 Colao A, Pivonello R, Auriemma RS, Briganti F, Galdiero M, Tortora F, Caranci F, Cirillo S \& Lombardi G. Predictors of tumor shrinkage after primary therapy with somatostatin analogues in acromegaly: a prospective study in 99 patients. Journal of Clinical Endocrinology and Metabolism 200691 2112-2118.

7 Turner HE, Vadivale A, Keenan J \& Wass JA. A comparison of lanreotide and octreotide LAR for treatment of acromegaly. Clinical Endocrinology 199951 275-280.

8 Cozzi R, Attanasio R, Montini M, Pagani G, Lasio G, Lodrini S, Barausse M, Albizzi M, Dallabonzana D \& Pedroncelli AM. Four-year treatment with octreotide-LAR in 110 acromegalic patients: the predictive value of short-term results by ROC analysis. Journal of Clinical Endocrinology and Metabolism 2003 88 3090-3098.

9 Colao A, Ferone D, Marzullo P, Cappabianca P, Cirillo S, Boerlin V, Lancranjan I \& Lombardi G. Long-term effects of depot long-acting somatostatin analog octreotide on hormone levels and tumor mass in acromegaly. Journal of Clinical Endocrinology and Metabolism $2001862779-2786$.

10 Colao A \& Lombardi G. Growth hormone and prolactin excess. Lancet 1998352 1455-1461.

11 Giustina A, Barkan A, Casanueva FF, Cavagnini F, Frohman L, Ho K, Veldhuis J, Wass J, Von Werder K \& Melmed S. Criteria for cure of acromegaly: a consensus statement. Journal of Clinical Endocrinology and Metabolism 200085 526-529.

12 Colao A, Pivonello R, Rosato F, Tita P, De Menis E, Barreca A, Ferrara R, Mainini F, Arosio M \& Lombardi G. First-line octreotideLAR therapy induces tumour shrinkage and controls hormone excess in patients with acromegaly: results from an open, prospective, multicentre trial. Clinical Endocrinology $2006 \mathbf{6 4}$ 342-351.

13 American Diabetes Association Diagnosis and Classification of Diabetes Mellitus. Diabetes Care 200629 S43-S48. 
14 Matthews DR, Hosker JP, Rudenski AS, Naylor BA, Treacher DF \& Turner RC. Homeostasis model assessment: insulin resistance and $\beta$-cell function from fasting plasma glucose and insulin concentrations in man. Diabetologia $1985 \mathbf{2 8} 412-419$.

15 Colao A, Ferone D, Lastoria S, Marzullo P, Cerbone G, Di Sarno A, Longobardi S, Merola B, Salvatore M \& Lombardi G. Prediction of efficacy of octreotide therapy in patients with acromegaly. Journal of Clinical Endocrinology and Metabolism $1996812356-2362$.

16 Sheppard MC. Primary medical therapy for acromegaly. Clinical Endocrinology $2003 \mathbf{5 8} 387-399$.

17 Colao A, Ferone D, Marzullo P \& Lombardi G. Systemic complications of acromegaly: epidemiology, pathogenesis and management. Endocrine Reviews 200425 102-152.

18 Ayuk J, Clayton RN, Holder G, Sheppard MC, Stewart PM \& Bates AS. Growth hormone and pituitary radiotherapy, but not serum insulin-like growth factor-I concentrations, predict excess mortality in patients with acromegaly. Journal of Clinical Endocrinology and Metabolism 200489 1613-1617.

19 Kauppinen-Makelin R, Sane T, Reunanen A, Valimaki MJ, Niskanen L, Markkanen H, Loyttyniemi E, Ebeling T, Jaatinen P, Laine H, Nuutila P, Salmela P, Salmi J, Stenman VH, Vükari J \& Voutilainen E. A nationwide survey of mortality in acromegaly. Journal of Clinical Endocrinology and Metabolism 2005904081 4086.

20 Colao A, Martino E, Cappabianca P, Cozzi R, Scanarini M, Ghigo E \& ALICE Study Group. First-line therapy of acromegaly: a statement of the ALICE (Acromegaly primary medical treatment Learning and Improvement with Continuous Medical Education) Study Group. Journal of Clinical Investigation 200629 1017-1020.

21 Chanson P, Boerlin V, Ajzenberg C, Bachelot Y, Benito P, Bringer J, Caron P, Charbonnel B, Cortet C, Delemer B, Escobar-Jimenez F, Foubert L, Gaztambide S, Jockenhoovel F, Kuhn JM, Leclere J, Lorcy Y, Perlemuter L, Prestele H, Roger P, Rohmer V, Santen R, Sassdas G, Scherbaum WA, Schopohl J, Torres E, Varela C, Villamil F \& Webb SM. Comparison of octreotide acetate LAR and lanreotide SR in patients with acromegaly. Clinical Endocrinology 200053 577-586.

22 Lancranjan I, Bruns C, Grass P, Jaquet P, Jervell J, Kendall-Taylor P, Lamberts SW, Marbach P, Orskov H, Pagani G, Sheppard M \& Simionesan L. Sandostatin LAR: a promising therapeutic tool in the management of acromegalic patients. Metabolism $1996 \mathbf{4 5}$ 67-71.

23 Ayuk J, Stewart SE, Stewart PM \& Sheppard MC. Long-term safety and efficacy of depot long-acting somatostatin analogues for the treatment of acromegaly. Journal of Clinical Endocrinology and Metabolism 200287 4142-4146.

24 Herman-Bonert VS, Zib K, Scarlett JA \& Melmed S. Growth hormone receptor antagonist therapy in acromegalic patients resistant to somatostatin analogs. Journal of Clinical Endocrinology and Metabolism $2000 \mathbf{8 5} 2958-2961$.
25 Drake WM, Parkinson C, Akker SA, Monson JP, Besser GM \& Trainer PJ. Successful treatment of resistant acromegaly with a growth hormone receptor antagonist. European Journal of Endocrinology $2001 \mathbf{1 4 5}$ 451-458.

26 Colao A, Pivonello R, Auriemma RS, De Martino MC, Bidlingmaier M, Briganti F, Tortora F, Burman P, Kourides IA, Strasburger CJ \& Lombardi G. Efficacy of 12-month treatment with the $\mathrm{GH}$ receptor antagonist pegvisomant in patients with acromegaly resistant to long-term, high-dose somatostatin analog treatment: effect on IGF-I levels, tumor mass, hypertension and glucose tolerance. European Journal of Endocrinology $2006 \mathbf{1 5 4}$ 467-477.

27 Schreiber I, Buchfelder M, Droste M, Forssmann K, Mann K, Saller B, Strasburger CJ \& the German Pegvisomant Investigators. Treatment of acromegaly with the $\mathrm{GH}$ receptor antagonist pegvisomant in clinical practice: safety and efficacy evaluation from the German Pegvisomant Observational Study. European Journal of Endocrinology 2007156 75-82.

28 Giusti M, Ciccarelli E, Dallabonzana D, Delitala G, Faglia G, Liuzzi A, Gussoni G \& Giordano G. Clinical results of long-term slow-release lanreotide treatment of acromegaly. European Journal of Clinical Investigation 199727 277-284.

29 Baldelli R, Battista C, Leonetti F, Ghiggi MR, Ribaudo MC, Paoloni A, D'Amico E, Ferretti E, Baratta R, Liuzzi A, Trischitta V \& Tamburrano G. Glucose homeostasis in acromegaly: effects of long-acting somatostatin analogues treatment. Clinical Endocrinology 200359 492-499.

30 Barkan AL, Burman P, Clemmons DR, Drake WM, Gagel RF, Harris PE, Trainer PJ, van der Lely AJ \& Vance ML. Glucose homeostasis and safety in patients with acromegaly converted from long-acting octreotide to pegvisomant. Journal of Clinical Endocrinology and Metabolism 2005 90 5684-5691.

31 Freda PU. Somatostatin analogs in acromegaly. Journal of Clinical Endocrinology and Metabolism 200287 3013-3018.

32 Colao A, Filippella M, Pivonello R, Di Somma C, Faggiano A \& Lombardi G. Combined therapy of somatostatin analogues and dopamine agonists in the treatment of pituitary tumours. European Journal of Endocrinology 2007156 S57-S63.

33 Feenstra J, de Herder WW, ten Have SM, van den Beld AW, Feelders RA, Janssen JA \& van der Lely AJ. Combined therapy with somatostatin analogues and weekly pegvisomant in active acromegaly. Lancet $20053651644-1646$.

Received 10 June 2007

Accepted 10 August 2007 